\title{
Сравнительная оценка результатов хирургического лечения варикоцеле
}

\begin{abstract}
Цель работы: улучшение результатов хирургического лечения варикоцеле путём совершенствования хирургической тактики. Материалы и методы. В основу исследования включены результаты лечения 376 больных с левосторонней варикоцеле, поступивших в урологическое отделение 2-й клиники Самаркандского государственного медицинского института. В зависимости от способа оперативного вмешательства были выделены 2 группы больных. В 2005-2010 гг. 181 больному произведены общепринятые оперативные вмешательства (операции Иваниссевича или Паломо), которые составили группу сравнения. С 2011 по 2018 г. 195 больным произведены субингвинальные селективные операции (антеградная эндоваскулярная склеротерапия левосторонней тестикулярной вены (ЛТВ) и операция Мармара), которые вошли в основную группу.

Результаты исследований и их обсуждение. По сравнению с 2005-2010 гг. частота послеоперационных осложнений снизилась с 12,7 до 2,6 \%, т. е. почти в 5 раз в основной группе. Антеграднаю ангиосклеротерапию ЛТВ больные легче переносят по сравнению с традиционными выполняемыми операциями, и данное оперативное вмешательство является экономически выгодным, поскольку сокращает продолжительность пребывания больных в стационаре по сравнению с другими оперативными вмешательствами.
\end{abstract}

Ключевые слова: варикоцеле; диагностика; лечение; операция Иваниссевича; операция Паломо; операция Мармара; антеградная эндоваскулярная склеротерапия; осложнение.

Постановка проблемы и анализ последних исследований и публикаций. Варикоцеле, или варикозное расширение вен гроздевидного сплетения, является довольно распространенным заболеванием, которое может приводить к морфофункциональным нарушениям тестикулярной ткани. По данным ВОЗ (1992), заболевание встречается в 36 \% мужской популяции. Частота варикоцеле у мальчиков в возрасте до 10 лет составляет 1 \%, в возрасте от 10 до 25 лет варьирует от 9 до 25,8 \%, средняя составляет 16,3 \%. В возрасте 50-80 лет частота возникновения варикоцеле увеличивается до 75-77,3 \%, таким образом, прибавляя в среднем по 10 \% каждые 10 лет жизни [2, 5, 8, 11].

В зависимости от метода лечения рецидив варикоцеле встречается в 7-43 \% случаев. В литературе постоянно обсуждаются результаты различных способов лечения варикоцеле, однако единого мнения касательно патогенеза и лечения этой патологии до сих пор нет. По мнению многих исследователей, основным методом лечения варикоцеле является хирургический, который направлен на прерывание венозного рефлюкса и устранение гемодинамических нарушений венозной системы яичка [4, 7, 9, 13]. Применяемые в настоящее время пособия подразделяют на две группы: сохраняющие ренокавальный шунт (проксимальный тестикуло-илиакальный и проксимальный тестикуло-сафенный сосудистые анастомозы) и не сохраняющие ренокавальный шунт (супраингвинальные неселективные, супраингвинальные селективные, субингвинальные селективные). В по- следние годы повсеместно большую популярность приобрела рентгеновская эндоваскулярная операция [1, 3, 6, 10, 12]. Широкую популярность и рост числа внутрисосудистых вмешательств в лечении варикоцеле обеспечили малая травматичность, быстрое восстановление трудовой и социальной активности.

Цель работы: улучшение результатов хирургического лечения варикоцеле путем совершенствования хирургической тактики.

Материалы и методы. В основу исследования включены результаты лечения 376 больных с левосторонней варикоцеле, поступивших в урологическое отделение 2-й клиники (Научный центр детской хирургии: главврач д. м. н., профессор Ж. А. Шамсиев) Самаркандского государственного медицинского института.

В зависимости от способа оперативного вмешательства были выделены 2 группы больных. В 2005-2010 гг. 181 (48,1 \%) больному произведены общепринятые оперативные вмешательства (операции Иваниссевича или Паломо), которые составили группу сравнения.

Операция Иваниссевича была выполнена следующим образом: разрезом длиной около 4 см в левой подвздошной области на уровне передневерхней ости подвздошной кости послойно рассекали кожу, подкожную клетчатку, апоневроз наружной косой мышцы живота, раздвигали мышцы и обнажали забрюшинное пространство; париетальную брюшину отодвигали медиально, в ретро-перито- 
неальной клетчатке выделяли левую яичковую вену (рис. 1), освобождали ее на небольшом протяжении; вену перевязывали и пересекали между двумя лигатурами; операционную рану зашивали наглухо.

Операция Паломо была выполнена следующим образом. Под общим обезболиванием после обработки операционного поля по Гроссиха-Филончикову разрез длиной до 5-6 см проводили в левой подвздошной области на уровне spina iliaca anterior superior в направлении кожной складки. Рассекали кожу, подкожную клетчатку, томсонову фасцию и апоневроз наружной косой мышцы живота. Внутреннюю косую и поперечную мышцы разводили тупо по ходу волокон, как при аппендэктомии. Вскрывали поперечную фасцию живота и обнажали ретроперитонеальное пространство. Боковую и заднюю стенки брюшинного мешка отсепаровывали в пределах возможностей образованного операционного поля. Находили сосудисто-нервный пучок. Под тестикулярную артерию и вену подводили по одной лигатуре, которые использовали на этапах дальнейшего выделения со-

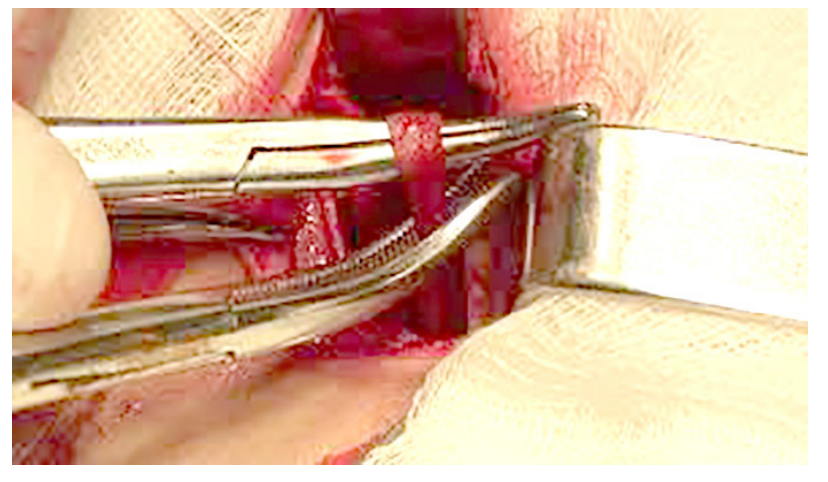

a судов. Артерию и вену препарировали на протяжении от места, находящегося на 5-6 см проксимальнее внутреннего пахового кольца, до места отхождения подпочечной ветви в области паранефральной клетчатки. В процессе выделения сосудов лигировали и пересекали все встречающиеся разветвления основного ствола тестикулярной вены. Так же поступали с бифуркацией основного ствола тестикулярной вены и ее подпочечной ветвью. Вены-сателлиты иссекали на максимально возможном протяжении (рис. 2). Иногда их трудно было обнаружить, в основном они находились в поясничном отделе рядом с основным стволом или в области забрюшинного отдела семенного канатика. После операции яичко кровоснабжается A. ductus deferentis, A. cremasterica. Венозный отток осуществляется по V. cremasterica и коллатералям.

С 2011 по 2018 гг. 195 (51,9 \%) больным произведены субингвинальные селективные операции (антеградной эндоваскулярной склеротерапии левосторонней тестекулярной вены (ЛТВ) и операция Мармара), которые вошли в основную группу.

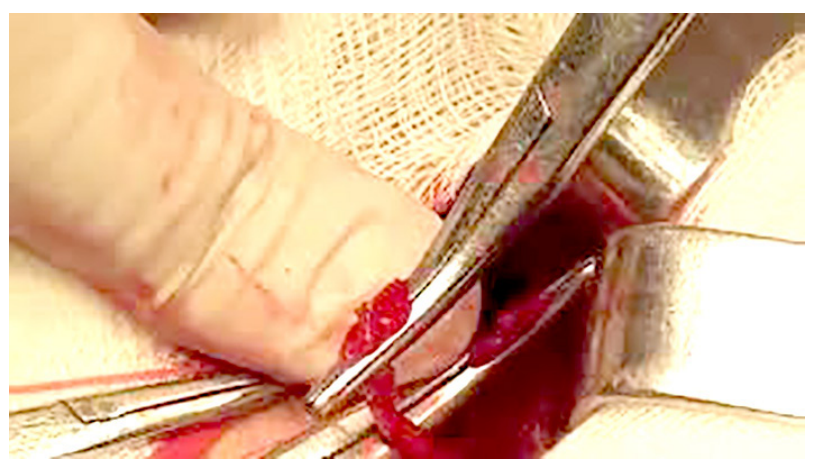

б

Рис. 1. Этапы операции Иваниссевича: а - выделение левой яичковой вены в области вливания в левую почечную вену; б - пересечение левой яичковой вены.

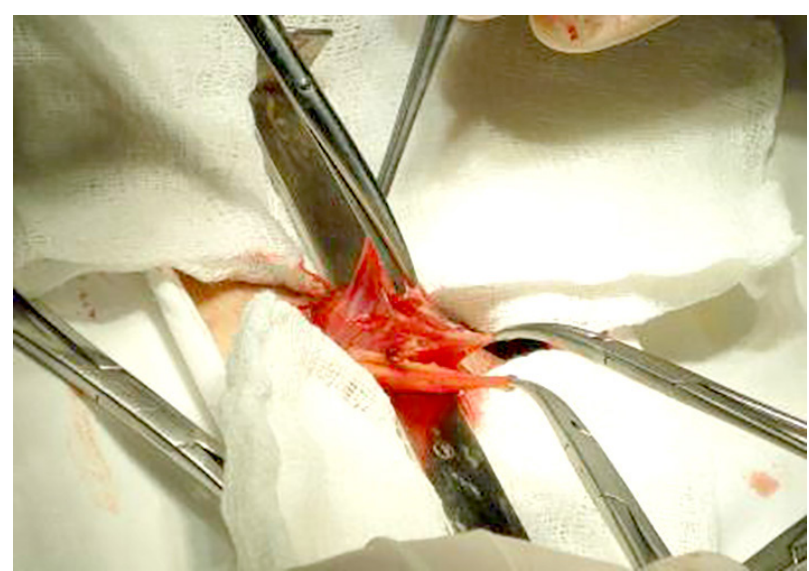

$\mathrm{a}$

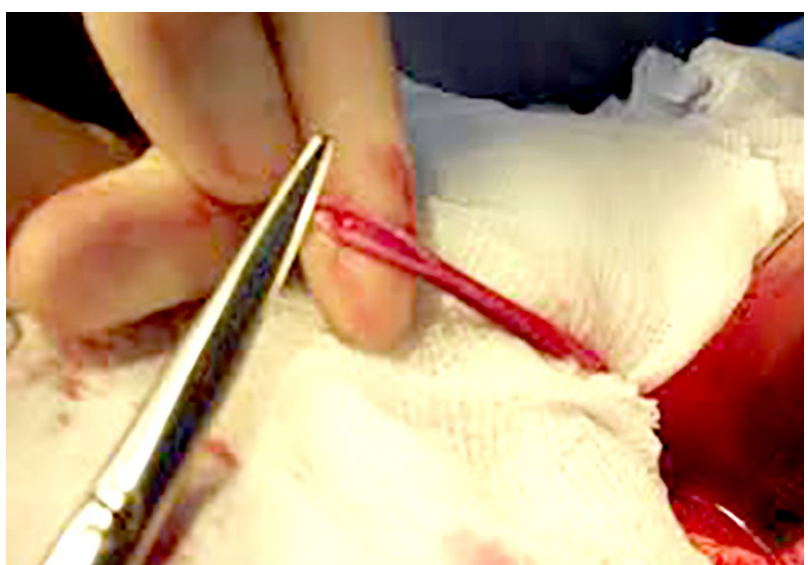

б

Рис. 2. Этапы операции Паломо: а - вскрытие забрюшинного пространства в левой подвздошной области; б - выделение левой яичковой артерии и вены. 
Для определения направления патологического кровотока, т. е. патологического рефлюкса крови, проводили УЗДПГ с использованием пробы Тромбетта.

При выполнении варикоцелэктомии до 2010 г. пользовались исключительно традиционными общепринятыми способами (табл. 1), которые имеют ряд серьезных и общеизвестных недостатков - высокая травматичность вмешательства, повышенный риск послеоперационных раневых осложнений, неудовлетворительные косметические результаты, длительный период ранней реабилитации и высокая частота рецидива заболевания. Указанные обстоятельства побудили нас к поиску более щадящих, менее травматичных и в то же время удобных для оператора ангиохирургических вмешательств.

С 2011 года при хирургическом лечении варикоцеле в зависимости от клинического течения заболевания и гемодинамического типа каждому больному выбираем индивидуальный, дифференцированный подход. Так, при реносперматическом I типе (120 - 61,5 \%) и смешанном типе с превалированием реносперматического рефлюкса (III А тип 19 - 9,7 \%) применяли антеградную ангиосклеротерапию левой тестикулярной вены (ЛТВ), при илеосперматическом II типе (42 - 21,5 \%) и смешанном типе с превалированием илеосперматического рефлюкса (III В тип 14 - 7,2 \%) варикоцелэктомию выполнено по Мармару (табл. 2).

Антеградная ангиосклеротерапия ЛТВ является малоинвазивным способом лечения варикоцеле, позволяющего значительно снизить вероятность возникновения послеоперационных осложнений и рецидива заболевания за счет патогенетически обоснованного полного прерывания патологического кровотока.

При этом для надежного предупреждения затекания склерозирующего вещества в почечную вену и его рефлюкса в вены гроздевидного сплетения в яичковую вену перед и после введения склерозирующего препарат вводится воздух.

Воздух, введенный перед и после введения склерозирующего препарата, закупоривая яичковую вену, препятствует рефлюксу и затеканию склерозанта в вены гроздевидного сплетения и почечную вену.

Антеградную ангиосклеротерапию ЛТВ проводили следующим образом (рис. 3).

Под общим наркозом, после обработки операционного поля йодом со спиртом, производится продольный разрез кожи длинной 1,5-2,0 см над проекцией наружного пахового кольца. Обнаруживается

Таблица 1. Распределение больных группы сравнения в зависимости от степени варикоцеле, гемодинамического типа и выбора оперативного вмешательства

\begin{tabular}{|c|c|c|c|c|c|c|}
\hline \multirow{3}{*}{$\begin{array}{c}\text { Степень } \\
\text { варикоцеле }\end{array}$} & \multicolumn{6}{|c|}{ Выбор оперативного вмешательства } \\
\hline & \multicolumn{3}{|c|}{ операция Иваниссевича } & \multicolumn{3}{|c|}{ операция Паломо } \\
\hline & I тип & II тип & III тип & I тип & II тип & III тип \\
\hline І степень & 1 & - & - & - & - & - \\
\hline II степень & 27 & 13 & 4 & 19 & 6 & 2 \\
\hline III степень & 34 & 12 & 12 & 28 & 16 & 7 \\
\hline Всего & 62 & 25 & 16 & 47 & 22 & 9 \\
\hline Итого & \multicolumn{3}{|c|}{103} & \multicolumn{3}{|c|}{78} \\
\hline
\end{tabular}

Таблица 2. Распределение больных основной группы в зависимости от степени варикоцеле, гемодинамического типа и выбора оперативного вмешательства

\begin{tabular}{|c|c|c|c|c|}
\hline \multirow{3}{*}{$\begin{array}{c}\text { Степень } \\
\text { варикоцеле }\end{array}$} & \multicolumn{4}{|c|}{ Выбор оперативного вмешательства } \\
\hline & \multicolumn{2}{|c|}{ антеградная ангиосклеротерапия ЛТВ } & \multicolumn{2}{|c|}{ операция Мармара } \\
\hline & I тип & III A тип & II тип & III В тип \\
\hline I степень & 1 & - & - & 1 \\
\hline II степень & 58 & 7 & 9 & 4 \\
\hline III степень & 61 & 12 & 33 & 9 \\
\hline Всего & 120 & 19 & 42 & 14 \\
\hline Итого & \multicolumn{2}{|c|}{139} & \multicolumn{2}{|c|}{56} \\
\hline
\end{tabular}




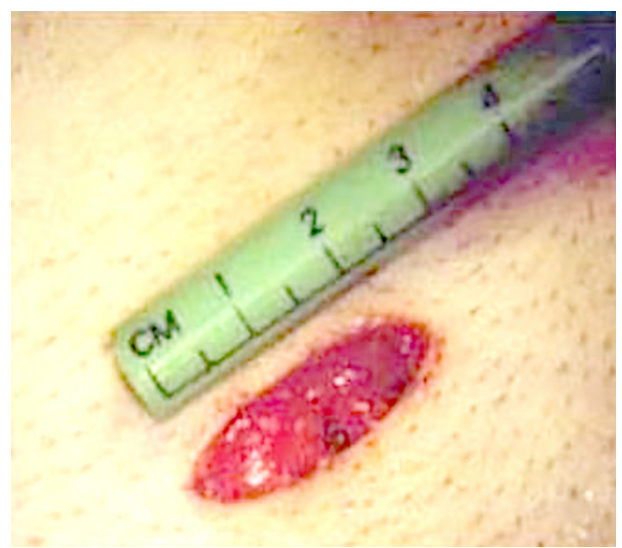

a

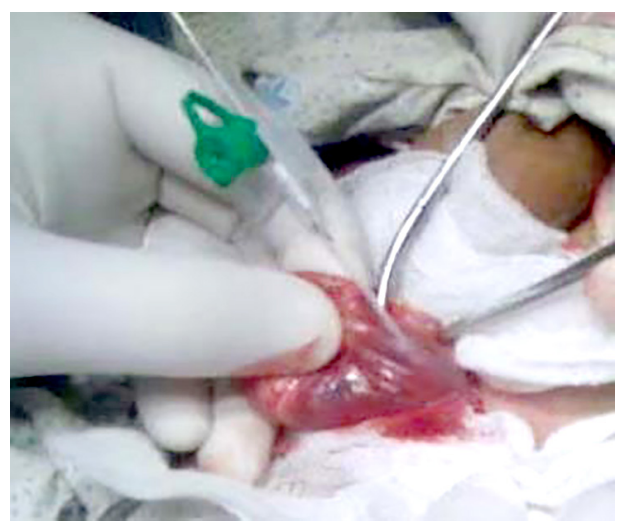

B

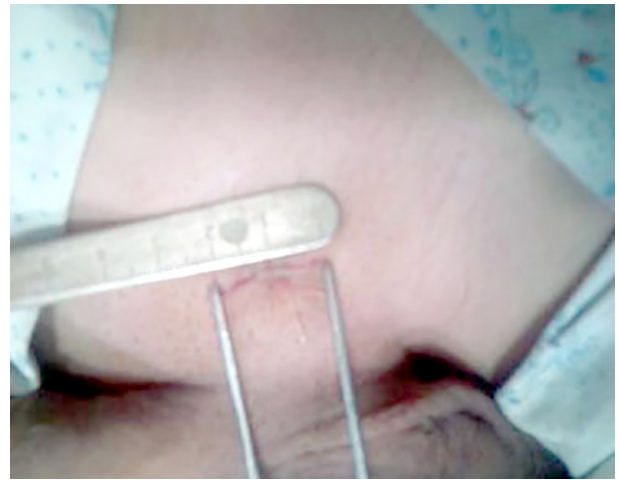

Д

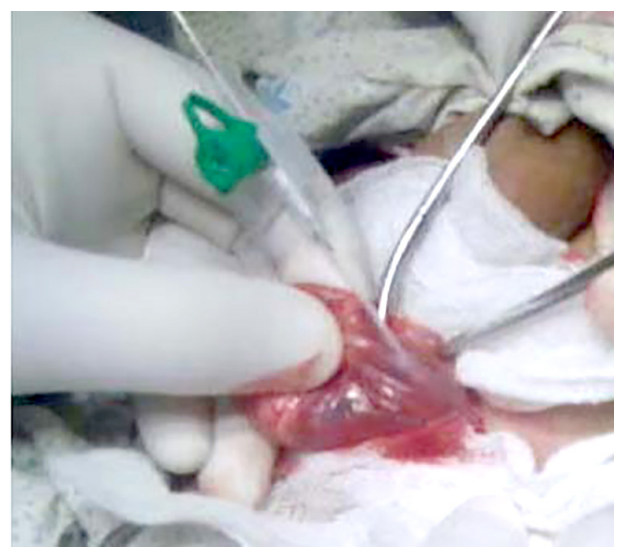

б
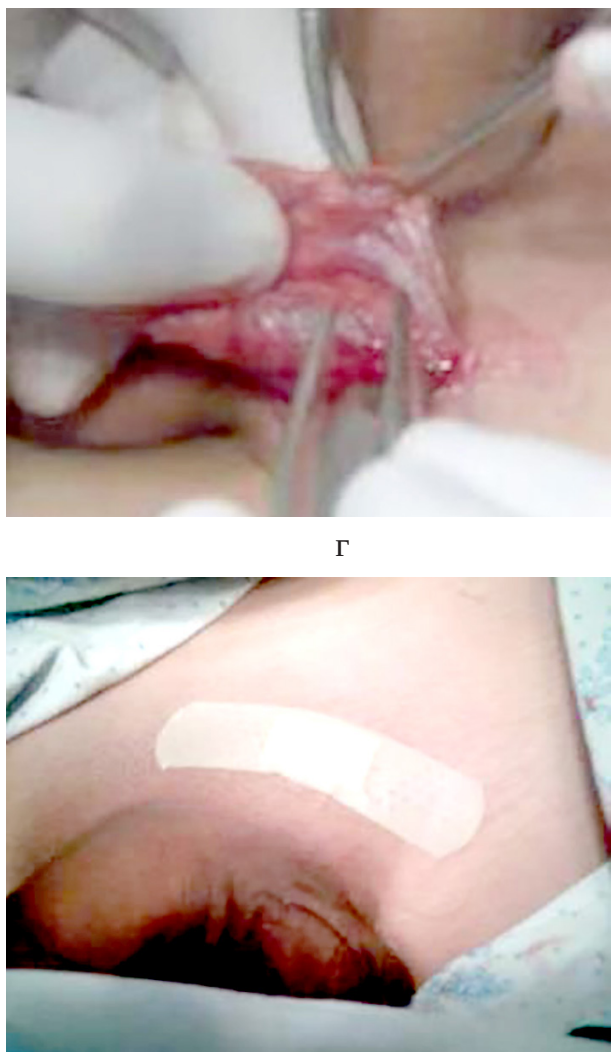

Рис. 3. Этапы антеградной эндоваскулярной склеротерапии ЛТВ: а - разрез на коже над проекцией наружного пахового кольца слева; б - пункция яичковой вены тонким катетором; в - ведение воздуха и склерозирующего препарата через тонкий катетер; г - удаление катетера; д - окончательный вид раны; е - асептическая повязка на рану.

яичковая вена, пунктируется тонким катетером, через который вводится 1,0 см³ воздуха, затем 2,0 мл склерозирующего препарата (этоксисклерол) и в завершении вводится ещё 1,0 см$^{3}$ воздуха. Катетер удаляется. Кожа ушивается одним узловым швом. На следующий день пациент выписывается домой.

Предлагаемый способ имеет ряд преимуществ:

- малоинвазивен;

- не требует дорогостоящего оборудования экономически эффективен;
- исключается затекание склерозирующего вещества в почечную вену и его рефлюкс в вены гроздевидного сплетения;

- надежно предупреждает развитие послеоперационных осложнений и рецидива заболевания;

- сокращаются сроки пребывания больных в стационаре.

Результаты исследований и их обсуждение. Совершенствование выбора тактики хирургичес- 
кого лечения варикоцеле, техники выполнения хирургического вмешательства, снижение травматичности оперативного вмешательства и другие новшества, разработанные и внедренные в рамках данного исследования, не могли не отразиться на непосредственных результатах ведения этой категории пациентов. Так, по сравнению с 2005-2010 гг. частота послеоперационных осложнений снизилась с 12,7 до 2,6 \%, т. е. почти в 5 раз (табл. 3).

Проанализированы отдалённые результаты у 229 (60,9 \%) из 376 оперированных больных по поводу варикоцеле (табл. 4). Для оценки отдалённых результатов больные подвергались тщательному анкетированию, амбулаторному и стационарному обследованию. Отдалённые результаты изучались в сроки от 1 года до 12 лет.

Одним из главных показателей, характеризующих эффективность оперативного вмешательства при варикоцеле, является частота рецидивов заболевания. При изучении характера рецидива сопоставляли гемодинамический тип варикоцеле.

Таблица 3. Частота послеоперационных осложнений у больных варикоцеле

\begin{tabular}{|c|c|c|c|c|c|c|c|c|c|c|}
\hline \multirow{4}{*}{ Вид осложнения } & \multicolumn{8}{|c|}{ Группа больных } & & \\
\hline & \multicolumn{4}{|c|}{ группа сравнения } & \multicolumn{4}{|c|}{ основная группа } & \multirow{2}{*}{\multicolumn{2}{|c|}{$\begin{array}{c}\text { Всего } \\
(n=376)\end{array}$}} \\
\hline & \multicolumn{2}{|c|}{$\begin{array}{c}\text { операция } \\
\text { Иваниссевича } \\
(\mathrm{n}=103)\end{array}$} & \multicolumn{2}{|c|}{$\begin{array}{c}\text { операция } \\
\text { Паломо } \\
(\mathrm{n}=78)\end{array}$} & \multicolumn{2}{|c|}{$\begin{array}{c}\text { антеградная } \\
\text { ангиосклеротерапия } \\
\text { ЛТВ }(\mathrm{n}=139)\end{array}$} & \multicolumn{2}{|c|}{$\begin{array}{c}\text { операция } \\
\text { Мармар } \\
(\mathrm{n}=56)\end{array}$} & & \\
\hline & абс. & $\%$ & абс. & $\%$ & абс. & $\%$ & абс. & $\%$ & абс. & $\%$ \\
\hline $\begin{array}{l}\text { Боль и дискомфорт в области } \\
\text { мошонки }\end{array}$ & 3 & 2,9 & 2 & 2,6 & 1 & 0,7 & 1 & 1,8 & 7 & 1,9 \\
\hline Гипотрофия яичка & 2 & 1,9 & 3 & 3,8 & 1 & 0,7 & - & - & 6 & 1,6 \\
\hline Гидроцеле & 4 & 3,9 & 1 & 1,3 & - & - & 1 & 1,8 & 6 & 1,6 \\
\hline Кровотечение & 2 & 1,9 & 1 & 1,3 & 1 & 0,7 & - & - & 4 & 1,1 \\
\hline $\begin{array}{l}\text { Нагноение послеоперационной } \\
\text { раны }\end{array}$ & 2 & 1,9 & 1 & 1,3 & - & - & - & - & 3 & 0,8 \\
\hline Повышение температуры & 1 & 0,9 & 1 & 1,3 & - & - & - & - & 2 & 0,5 \\
\hline Всего осложнений & 14 & 13,6 & 9 & 11,5 & 3 & 2,1 & 2 & 3,6 & 28 & 7,4 \\
\hline Число больных с осложнениями & 8 & 7,8 & 6 & 7,7 & 2 & 1,4 & 1 & 1,8 & 17 & 4,5 \\
\hline
\end{tabular}

Таблица 4. Частота рецидивов в отдаленном послеоперационном периоде у больных с варикоцеле

\begin{tabular}{|c|c|c|c|c|c|c|c|c|c|c|}
\hline \multirow{4}{*}{$\begin{array}{c}\text { Гемодинами- } \\
\text { ческий тип }\end{array}$} & \multicolumn{8}{|c|}{ Количество рецидивов в зависимости от вида операции } & \multirow{3}{*}{\multicolumn{2}{|c|}{$\begin{array}{c}\text { Всего } \\
(n=376)\end{array}$}} \\
\hline & \multicolumn{4}{|c|}{ группа сравнения } & \multicolumn{4}{|c|}{ основная группа } & & \\
\hline & \multicolumn{2}{|c|}{$\begin{array}{c}\text { операция } \\
\text { Иваниссевича } \\
(n=103)\end{array}$} & \multicolumn{2}{|c|}{$\begin{array}{c}\text { операция Паломо } \\
\text { (n=78) }\end{array}$} & \multicolumn{2}{|c|}{$\begin{array}{c}\text { антеградная } \\
\text { ангиосклеротерапия } \\
\text { ЛТВ (n=139) }\end{array}$} & \multicolumn{2}{|c|}{$\begin{array}{c}\text { операция } \\
\text { Мармар (n=56) }\end{array}$} & & \\
\hline & абс. & $\%$ & абс. & $\%$ & абс. & $\%$ & абс. & $\%$ & абс. & $\%$ \\
\hline \multirow[t]{2}{*}{ І тип } & 36 & 34,9 & 25 & 32,0 & 78 & 56,1 & - & - & 139 & 36,9 \\
\hline & 2 & 5,5 & 1 & 4,0 & - & - & - & - & 3 & 2,1 \\
\hline \multirow[t]{2}{*}{ II тип } & 15 & 14,6 & 13 & 16,7 & - & - & 29 & 51,8 & 57 & 15,1 \\
\hline & 6 & 40,0 & 3 & 23,1 & - & - & 1 & 3,4 & 10 & 17,5 \\
\hline \multirow[t]{2}{*}{ III тип } & 10 & 9,7 & 6 & 7,7 & - & - & - & - & 16 & 4,2 \\
\hline & 4 & 40,0 & 2 & 33,3 & - & - & - & - & 6 & 37,5 \\
\hline \multirow[t]{2}{*}{ III A тип } & - & - & - & - & 11 & 7,9 & - & - & 11 & 2,9 \\
\hline & - & - & - & - & 1 & 9,1 & - & - & 1 & 9,1 \\
\hline \multirow[t]{2}{*}{ III В тип } & - & - & - & - & - & - & 6 & 10,7 & 6 & 1,6 \\
\hline & - & - & - & - & - & - & - & - & - & - \\
\hline \multirow[t]{2}{*}{ Всего } & 61 & 59,2 & 44 & 56,4 & 89 & 64,0 & 35 & 62,5 & 229 & 60,9 \\
\hline & 12 & 19,7 & 6 & 13,6 & 1 & 1,1 & 1 & 2,8 & 20 & 8,7 \\
\hline
\end{tabular}

Примечание: в числителе количество наблюдений в отдаленном послеоперационном периоде, в знаменателе количество рецидивов в отдаленном послеоперационном периоде. 
Из 229 больных, обследованных в отдалённые сроки, рецидив варикоцеле отмечен у 20 (8,7 \%) больных, при этом в группе пациентов, оперированных в 2005-2010 гг., этот показатель достигал 17,1 \%. В последующем благодаря применению вышеперечисленных инноваций и мер профилактики заболевания частоту рецидивов заболевания удалось снизить в основной группе больных до 1,6 \%.

При ретроспективном анализе отдалённых результатов подавляюще большинство количество больных с рецидивами были II и III типа (7,4 \%).

Выводы. 1. Причиной рецидивов варикоцеле явились неучтённое во время первичной операции различные гемодинамические типы венозного оттока по внутренней семенной вене. Перспективой улучшения результатов хирургического лечения варикозного расширения вен семенного канати- ка является индивидуализация метода операции с учетом типа патологического рефлюкса.

2. Антеградная ангиосклеротерапия ЛТВ легче переносится больными по сравнению с традиционными выполняемыми операциями. Внедрение разработанного нами способа и алгоритма хирургического лечения варикоцеле демонстрирует меньшую частоту осложнений $(2,6 \%)$ и рецидивов $(1,6 \%)$ по сравнению с общепринятыми традиционными методами операций (осложнения $12,7 \%$, рецидив - $17,1 \%)$.

3. Антеградная ангиосклеротерапия ЛТВ одна из наиболее простых и малотравматичных методов ликвидации варикоцеле. Данная операция является экономически выгодной, сокращает продолжительность пребывания больных в стационаре по сравнению с другими оперативными вмешательствами.

\section{СПИСОК ЛИТЕРАТУРЫ}

1. О вариантной анатомии сосудов пахового канала / Н. В. Антипов, А. Б. Зарицкий, И. В. Фесак [и др.] // Клінічна анатомія та оперативна хірургія. - 2010. - Т. 9, № 3. - С. 36-38. 2. Хирургическое лечение варикоцеле у мужчин с бесплодием / С. И. Гамидов, А. А. Павловичев, С. В. Андранович [и др.] // Фарматека. - 2010. - № 18-19. - С. 44-48.

3. Лельчук С. А. Роль варикоцеле и его оперативного лечения в нарушении репродуктивной функции (обзор литературы) / С. А. Лельчук, Ф. Ф. Антоненко, Э. А. Щербавская // Репродуктивное здоровье детей и подростков. - 2009. - № 3. - С. 77-84.

4. Умаров Б. А. Сравнительная оценка результатов хирургического лечения варикоцеле Б. А. Умаров // Вестник Кыргызско-Российского славянского университета. - 2012. Т. 12, № 9. - С. 129-131.

5. Шамраев С. Н. Ближайшие результаты различных современных методов хирургического лечения варикоцеле / С. Н. Шамраев, А. Я. Канана // Актуальні проблеми сучасної медицини: Вісник української медичної стоматологічної академії. - 2011. - Т. 11, № 4-1 (36). - С. 108-110.

6. Agarwal A. Insight into oxidative stress in varicocele-associated male infertility: part 1 / A. Agarwal, A. Hamada, S. C. Esteves // Nature Reviews Urology. - 2012. - Vol. 9, No. 12. - P. 678.

7. DNA damage in spermatozoa from infertile men with varicocele evaluated by sperm chromatin dispersion and DBD-FISH / E. I. Cortés-Gutiérrez, M. I. Dávila-Rodríguez,
J. L. Fernández, [et al.] //Archives of Gynecology and Obstetrics. - 2016. - Vol. 293, No. 1. - P. 189-196.

8. Optimization of surgical treatment of varicose disease of lower extremities / S. S. Davlatov, U. A. Sherbekov, F. F. Juraeva, [et al.] // Проблемы современной науки и образования. - 2017. - №. 26. - C. 85-88.

9. Morphologic evaluation of the dilated spermatic veins in children with varicocele / S. A. Muhitdinovich, K. N. Daminovich, B. I. Muhamedovich, [et al.] // Медицинский вестник Северного Кавказа. - 2018. - Т. 13, №. 3. - С. 517-519.

10. Scanning electronic microscopy of spermatic veins at varicocele / S. A. Muxitdinovich, K. N. Daminovich, B. I. Mukhamedovich, [et al.] // Достижения науки и образования. - 2017. - Том 22, № 9. - С. 58-61.

11. Effect of smoking on the functional aspects of sperm and seminal plasma protein profiles in patients with varicocele / R. M. Fariello, J. R. Pariz, D. M. Spaine [et al.] // Human Reproduction. - 2012. - Vol. 27, No. 11. - P. 3140-3149.

12. Optimization of surgical treatment of varicose disease of lower extremities / D. S. Sulaymonovich, S. U. Ahrarovich, J. F. Farmonovna, [et al.] // Проблемы современной науки и образования. - 2017. - №. 26 (108). - С. 85-88.

13. Zohdy W. Impact of varicocelectomy on gonadal and erectile functions in men with hypogonadism and infertility / W. Zohdy, S. Ghazi, M. Arafa // The Journal of Sexual Medicine. - 2011. Vol. 8, No. 3. - P. 885-893.

\section{REFERENCES}

1. Antipov, N.V., Zaritskiy, A.B., \& Fesak, I.V. (2010). O variantnoy anatomii sosudov pakhovogo kanala [On the variant anatomy of the vessels of the inguinal canal]. Klinichna anatomiia ta operatyvna khirurhiia - Clinical Anatomy and Operative Surgery, 9 (3), 36-38 [in Russian].

2. Gamidov, S.I., Pavlovichev, A.A., \& Andranovich, S.V. (2010). Khirurgicheskoe lechenie varikotsele u muzhchin s besplodiem [Surgical treatment of varicocele in men with infertility]. Farmateka - Pharmateka, 8-19, 44-48 [in Russian] 3. Antonenko, F.F., Shcherbavskaya, E.A., \& Lelchuk, S.A.. (2009). Rol varikotsele i ego operativnogo lecheniya v narushenii reproduktivnoy funktsiy (obzor literatury) [The role of varicocele and its surgical treatment in impaired reproductive function (literature review)]. Reproduktivnoye zdorovye detey i podrostkov - Reproductive Health of Children and Adolescents, 3, 77-84 [in Russian]. 
4. Umarov, B.A. (2012). Sravnitelnaya otsenka rezultatov khirurgicheskogo lecheniya varikotsele [Comparative evaluation of the results of surgical treatment of varicocele]. Vestnik Kyrgyzsko-Rossiyskogo slavyanskogo universiteta - Bulletin of the Kyrgyz-Russian Slavic University, 12 (9), 129-131 [in Russian].

5. Shamrayev, S.N., \& Kanana, A.Ya. (2011). Blizhayshie rezultaty razlichnykh sovremennykh metodov khirurgicheskogo lecheniya varikotsele [The immediate results of various modern methods of surgical treatment of varicocele]. Aktualni problemy suchasnoi meditsyny: Visnyk ukrainskoi medychnoi stomatolohichnoi akademii - Topical problems of modern medicine: Bulletin of the Ukrainian Medical Dental Academy, 11, 4-1 (36), 108-110 [in Russian].

6. Agarwal, A., Hamada, A., \& Esteves, S. C. (2012). Insight into oxidative stress in varicocele-associated male infertility: part 1. Nature Reviews Urology, 9 (12), 678.

7. Cortés-Gutiérrez, E.I., Dávila-Rodríguez, M.I., Fernández, J.L., López-Fernández, C., Aragón-Tovar, A.R., UrbinaBernal, L.C., \& Gosálvez, J. (2016). DNA damage in spermatozoa from infertile men with varicocele evaluated by sperm chromatin dispersion and DBD-FISH. Archives of Gynecology and Obstetrics, 293 (1), 189-196.

8. Davlatov, S.S., Sherbekov, U.A., Juraeva, F.F., \& Yusupalieva, K.B.Q. (2017). Optimization of surgical treatment of varicose disease of lower extremities. Problemy sovremennoy nauki i obrazovanii - Problems of Modern Science and Education, 26 (108), 85-88.

9. Muhitdinovich, S.A., Daminovich, K.N., Muhamedovich, B.I., Azamatovich, S.J., \& Anatolyevich, T.O. (2018). Morphologic evaluation of the dilated spermatic veins in children with varicocele. Meditsinskiy vestnik Severnogo Kavkaza - Medical Bulletin of the North Caucasus, 13 (3), 517-519.

10. Muxitdinovich, S.A., Daminovich, K.N., Mukhamedovich, B.I., Azamatovich, S.J., \& Suratovna, I.S. (2017). Scanning electronic microscopy of spermatic veins at varicocele. Dostizheniye nauki i obrazovaniya - Achievements of Science and Education, (9 (22)), 58-61.

11. Fariello, R.M., Pariz, J.R., Spaine, D.M., Gozzo, F.C., Pilau, E.J., Fraietta, R., ... \& Cedenho, A.P. (2012). Effect of smoking on the functional aspects of sperm and seminal plasma protein profiles in patients with varicocele. Human Reproduction, 27 (11), 3140-3149.

12. Sulaymonovich, D.S., Ahrarovich, S.U., Farmonovna, J.F., \& Qizi, Y.K.B. (2017). Optimization of surgical treatment of varicose disease of lower extremities. Problemy sovremennoy nauki o obrazovaniya - Problems of Modern Science and Education, 26 (108), 85-88

13. Zohdy, W., Ghazi, S., \& Arafa, M. (2011). Impact of varicocelectomy on gonadal and erectile functions in men with hypogonadism and infertility. The Journal of Sexual Medicine, 8 (3), 885-893.

Получено 29.05.2019

Электронный адресс для переписки: sammi@sammi.uz

\author{
A. M. SHAMSIEV, SH. A. YUSUPOV, N. D. KODIROV
}

Samarkand State Medical Institute. Samarkand, Uzbekistan

\title{
COMPARATIVE EVALUATION OF THE RESULTS OF SURGICAL TREATMENT OF VARICOCELE
}

The aim of the work: to improve the surgical treatment of varicocele via enhancing surgical tactics.

Materials and Methods. The study included the results of the treatment of 376 patients with left-sided varicocele who were admitted to the Urology Department of the Clinic No.2 of the Samarkand State Medical Institute. Depending on the method of surgical intervention, 2 groups of patients were identified. In 2005-2010 181 patients underwent conventional surgical interventions (Ivanissevich or Palomo operations), which made up the comparison group. From 2011 to 2018195 patients underwent subinguinal selective surgeries (antegrade endovascular sclerotherapy of the left-sided testicular vein (LTV) and Marmara surgery), which were included in the main group. Results and Discussion. Compared with 2005-2010 the incidence of postoperative complications decreased from 12.7 to $2.6 \%$, i.e. almost 5 times lower in the main group. Antegrade angiosclerotherapy of LTV is easier for patients compared to traditional operations and this operation is economically advantageous, it reduces the length of hospital stay in comparison with other surgical interventions.

Key words: varicocele; diagnosis; treatment; Ivanissevich operation; Palomo operation; Marmara operation; antegrade endovascular sclerotherapy; complication. 
А. М. ШАМСІєВ, Ш. А. ЮСУПОВ, Н. Д. КОДИРОВ

Самаркандський державний медичний інститут, Республіка Узбекистан

\section{ПОРІВНЯЛЬНА ОЦІКА РЕЗУЛЬТАТІВ ХІРУРГІЧНОГО ЛІКУВАННЯ ВАРИКОЦЕ.ЛЕ}

Мета роботи: покращення результатів хірургічного лікування варикоцеле шляхом удосконалення хірургічної тактики.

Матеріали і методи. В основу дослідження включено результати лікування 376 пацієнтів із лівостороннім варикоцеле, які проходили лікування в урологічному відділенні 2-ї клініки Самаркандського державного медичного інституту. Залежно від способу операційного втручання виділено 2 групи хворих. У 2005-2010 рр. 181 пацієнтові виконано загальноприйняті операційні втручання (операції Іванісевича або Паломо), які склали групу порівняння. 32011 по 2018 р. 195 хворим проведено субінгвінальні селективні операції (антеградна ендоваскулярна склеротерапія лівосторонньої тестикулярної вени (ЛТВ) та операція Мармара), які склали основну групу.

Результати досліджень та їх обговорення. Порівняно з 2005-2010 рр. частота післяопераційних ускладнень знизилась з 12,7 до 2,6\%, тобто майже у 5 разів у основній групі. Антеградна ангіосклеротерапія ЛТВ краще переноситься хворими порівняно 3 традиційними операціями. Окрім того, дане операційне втручання є економічно вигідним, оскільки скорочує тривалість перебування хворих у стаціонарі порівняно з іншими видами хірургічних втручань при варикоцеле.

Ключові слова: варикоцеле; діагностика; лікування; операція Іванісевича; операція Паломо; операція Мармара; антеградна ендоваскулярна склеротерапія; ускладнення. 